\title{
Nomogram for predicting reoperation following internal fixation of nondisplaced femoral neck fractures in elderly patients
}

Jian Zhu ${ }^{1,2,3,4 \dagger}$, Hongzhi Hu ${ }^{5 \dagger}$, Xiangtian Deng ${ }^{1,2,3,4 \dagger}$, Yiran Zhang ${ }^{1,2,3,4}$, Xiaodong Cheng ${ }^{2,3,4}$, Zhanchao Tan 2,3,4, Yanbin Zhu Z, $3,4^{2}$ and Yingze Zhang ${ }^{1,2,34^{*}}$

\begin{abstract}
Objective: We aimed to evaluate risk factors and develop a nomogram for reoperation after internal fixation of nondisplaced femoral neck fractures (FNFs) in elderly patients.

Methods: We conducted a retrospective study involving a total of 255 elderly patients who underwent closed reduction and internal fixation with cannulated screw system for nondisplaced FNFs between January 2016 and January 2019. We collected data on demographics, preoperative radiological parameters, surgery, serum biochemical markers, and postoperative rehabilitation. In addition, we performed univariate and multivariate logistic regression analyses to determine independent risk factors for reoperation, and then developed a nomogram to assess the risks of reoperation. Besides, discriminative ability, calibration, and clinical usefulness of the nomogram were evaluated using the concordance index (C-index), the receiver operating characteristic (ROC) curve, calibration curve and decision curve analysis (DCA), respectively. We employed bootstrap method to validate the performance of the developed nomogram.
\end{abstract}

Results: Our analysis showed that among the 255 patients, 28 (11.0\%) underwent reoperation due to osteonecrosis of the femoral head (14 cases), mechanical failure (8 cases) or nonunion (6 cases). All of the 28 patients underwent conversion surgery to arthroplasty. The multivariate logistic regression analysis demonstrated that preoperative posterior tilt angle $\geq 20^{\circ}$, Pauwel's III type, younger patients, preoperative elevated levels of alkaline phosphatase (ALP), preoperative hypoalbuminemia, and early postoperative weight-bearing were independent risk factors for reoperation. In addition, the C-index and the bootstrap value of the developed nomogram was $0.850(95 \% \mathrm{Cl}=$ 0.803-0.913) and 0.811, respectively. Besides, the calibration curve showed good consistency between the actual diagnosed reoperation and the predicted probability, while the DCA indicated that the nomogram was clinically valuable.

\footnotetext{
* Correspondence: zhangyingze4036@126.com

†Jian Zhu, Hongzhi Hu and Xiangtian Deng contributed equally to this work.

'School of Medicine, Nankai University, Tianjin 300071, People's Republic of China

${ }^{2}$ Department of Orthopedic Surgery, The Third Hospital of Hebei Medical University, Shijiazhuang 050051, People's Republic of China

Full list of author information is available at the end of the article
}

(C) The Author(s). 2021 Open Access This article is licensed under a Creative Commons Attribution 4.0 International License, which permits use, sharing, adaptation, distribution and reproduction in any medium or format, as long as you give appropriate credit to the original author(s) and the source, provide a link to the Creative Commons licence, and indicate if changes were made. The images or other third party material in this article are included in the article's Creative Commons licence, unless indicated otherwise in a credit line to the material. If material is not included in the article's Creative Commons licence and your intended use is not permitted by statutory regulation or exceeds the permitted use, you will need to obtain permission directly from the copyright holder. To view a copy of this licence, visit http://creativecommons.org/licenses/by/4.0/ The Creative Commons Public Domain Dedication waiver (http://creativecommons.org/publicdomain/zero/1.0/) applies to the data made available in this article, unless otherwise stated in a credit line to the data. 
Conclusions: Our analysis showed we successfully developed and validated a nomogram for personalized prediction of reoperation after internal fixation of nondisplaced FNFs in elderly patients. This model would help in individualized evaluation of the need for reoperation and inform strategies aimed at eliminating the need for the reoperation.

Keywords: Reoperation, Nondisplaced, Femoral neck fractures, Elderly, Nomogram

\section{Introduction}

Femoral neck fractures (FNFs) are common in geriatric population, accounting for 48 to $54 \%$ of hip fractures and $3.6 \%$ of the total fractures in adults [1]. Nearly $20 \%$ of all the FNFs are nondisplaced and often require surgical treatment $[2,3]$. Owing to the simplicity, safety, efficacy, and affordability of closed reduction and internal fixation with cannulated screw system, it is widely used in the treatment of elderly patients with nondisplaced FNFs [2, 4]. However, previous reports have shown unsatisfactory clinical outcomes because of nonunion events, fixation failure or femoral head necrosis, which leads to patient readmission and reoperation [5-7]. The reoperation rate after internal fixation of nondisplaced FNFs in elderly patients ranged between 8 and 19\% [8, 9]. Besides, reoperation is potentially devastating for the elderly patients, and the outcomes of salvage arthroplasty have been shown to be worse compared with those from the primary arthroplasty [10, 11]. Therefore, it is important to characterize reoperation and related predictors for better disease management.

Many studies have evaluated potential predictors of reoperation such as posterior tilt angle $\geq 20^{\circ}$, disruption of the medial cortex, higher level of fracture classification (Garden II or Pauwel's III), advanced age, female patients, high score of Charlson Comorbidity Index $(\geq 8)$, surgical delay, lower American Society of Anesthesiologists (ASA) grade, poor bone quality, and malnutrition [12-16]. However, serum biochemical markers and postoperative interventions were not included in the prediction system and thus were not integrated into the development of a nomogram. Therefore, there is need to develop an intuitive prediction model based on radiological measures, serum biochemical markers, and postoperative rehabilitative plans to inform treatment strategies.

Here, we evaluated multiple perioperative risk factors related to reoperation after internal fixation of nondisplaced FNF in elderly patients. Besides, we developed and validated a nomogram to intuitively predict personalized risks of reoperation to guide treatment options.

\section{Methods}

\section{Patients}

This study collected data from elder patients with nondisplaced FNFs and who underwent surgical treatment between January 2016 and January 2019. All the patients underwent closed reduction and internal fixation with cannulated screw system. The study followed the STROBE guidelines and was approved by the Institutional Review Board of the Third Hospital of Hebei Medical University (K2015-001-12). All the participants provided informed written consents.

\section{Inclusion and exclusion criteria}

We included patients aged $\geq 65$ years with a fresh nondisplaced FNF who had full baseline data. The patients were treated with closed reduction and internal fixation using a cannulated screw system and with a follow-up time $\geq 24$ months. On the other hand, patients with pathological fractures and those with concomitant multiple fractures at the ipsilateral lower limb were excluded from the study.

\section{Surgical technique}

Patient procedures were performed on a traction table without capsulotomies or hemarthrosis aspirations. After satisfactory reduction under fluoroscopy, three or four partially threaded, cancellous cannulated screws $(6.5 \mathrm{~mm}$; Stryker, Kalamazoo, MI, USA) were implanted percutaneously, in inverted triangle or rhombic configuration. The inferior screw was placed close to the femoral calcar, and all screws were inserted as deep as possible to purchase in the subchondral bone. After the operations, there was administration of intravenous cefazolin ( $2 \mathrm{~g} \times 3$ doses) for $24 \mathrm{~h}$ to prevent infection while low-molecular-weight heparin was used to prevent deep vein thrombosis (DVT). Besides, early weight-bearing was encouraged.

\section{Data collection}

Baseline data were obtained from medical records, outpatient follow-ups, and questionnaire surveys. A total of 255 patients were included in our study (Fig. 1). We collected data on patient demographics, radiological parameters, surgery, serum biochemical markers, as well as postoperative rehabilitation.

The demographic data included gender, age, injured side, smoking status, alcohol consumption, preoperative functional status, cerebrovascular disease, hypertension, diabetes mellitus, Charlson's weighted index of comorbidities (WIC), chronic kidney disease, and chronic obstructive pulmonary diseases (COPD). The Charlson's WIC is the most commonly used method in the evaluation of the severity of comorbidities in elderly patients. It is calculated based on the patient's medical history, 
Elderly patients with nondisplaced femoral neck fractures from 2016-2019 $(n=372)$

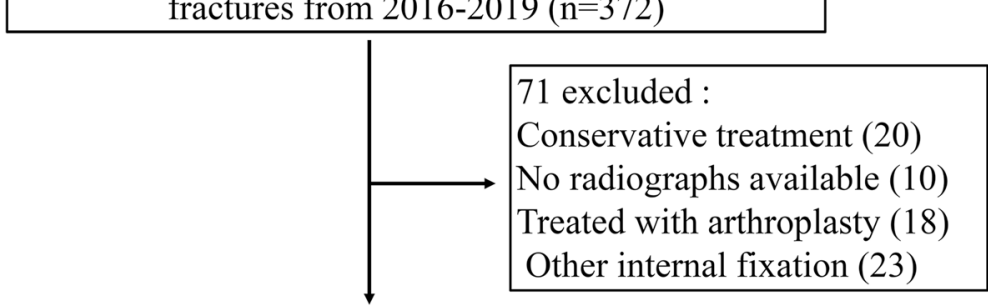

Elderly patients with nondisplaced femoral neck fractures treated by internal fixation with cannulated screw system $(n=301)$

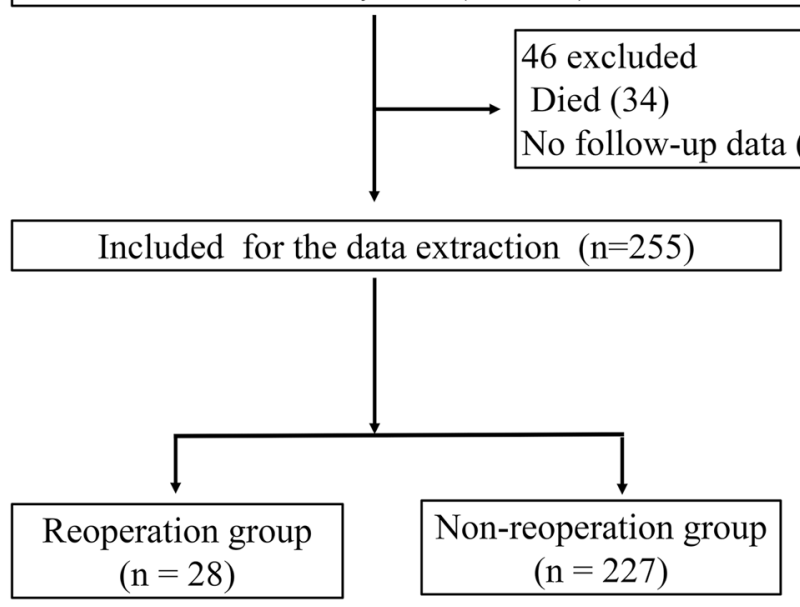

Fig. 1 Patient selection flowchart

prognosis, and weighted age [17]. Preoperative functional status was divided into either ambulatory aid or independent ambulator.

On the other hand, radiological parameters included Pauwel's angle and posterior tilt angle. The posterior tilt angle was measured on the lateral radiographs and defined as the angle between the mid-collum line and the radius collum line [18]. The radiographic measurements were performed by two experienced orthopedists who were not involved in the operation. Surgery-related information included interval to surgery, type of anesthesia, the American Society of Anesthesiologists (ASA) classification, and surgical time. Interval to surgery was defined as the duration between fracture diagnosis and the onset of surgery.

Serum biochemical markers included red blood cell (RBC) count, white blood cell (WBC) count, platelet (PLT) count, lymphocyte (LYM) count, hemoglobin (HGB) level, alanine transaminase (ALT), aspartate transaminase (AST), alkaline phosphatase (ALP), sodium concentration $\left(\mathrm{Na}^{+}\right)$, total protein (TP) level, albumin (ALB) level, and D-dimer level. Information on postoperative rehabilitation included interval to weight-bearing. The definition of weight-bearing was that patients began to ambulate with bilateral crutches or walker assistance. In addition, clinical outcomes at last follow-up, such as the Harris hip score and visual analogue scale (VAS), were also recorded.

Reoperation was defined as any operation performed due to complication after the primary internal fixation [19]. The complication included mechanical failure, nonunion of fracture, or avascular necrosis of the femoral head.

\section{Statistical analysis}

SPSS 26 software (IBM Corp., Armonk, NY, USA) was used for data analysis while $\mathrm{R}$ software (version 3.6.5, $\mathrm{R}$ Foundation for Statistical Computing, Vienna, Austria) with the "rms" package was used for nomogram construction. The interobserver reliability was measured using the kappa coefficient $(\kappa)$ for Pauwel's classification and intraclass correlation coefficient (ICC) for posterior tilt angle. The normality of population was evaluated using the Shapiro-Wilk test. Continuous data were presented as mean \pm standard deviation (SD) or median and interquartile range as evaluated with the Student $t$ test or Mann-Whitney $U$ test based on the data distribution. On the other hand, categorical data were 
presented as numbers (\%) and then compared with chisquared or Fisher's exact, as appropriate. The variables with $P<0.10$ in the univariable analyses were analyzed in a multivariable logistic regression to identify independent risk factors of reoperation. Thereafter, a nomogram was constructed using the independent risk factors obtained from the multivariable logistic regression analysis. The predictive ability and performance of the model was assessed with the concordance index (Cindex), the receiver operating characteristic (ROC) curve, calibration curve, as well as decision curve analysis (DCA). The C-index and the area under the ROC curve (AUC) were used to evaluate the predictive accuracy and discriminative ability of the nomogram [20]. The value of the C-index ranged between 0.5 and 1.0, where a larger value indicated more accuracy of the nomogram in distinguishing the subjects [21]. The relationship between the actual diagnosed reoperation and the predicted probability of the reoperation was evaluated with a calibration curve. In addition, the clinical usefulness of the nomogram was evaluated with the DCA based on the net benefit and threshold probabilities. A $P$ value < 0.05 was considered to be statistically significant. Finally, a corrected C-index was calculated through bootstrapping (1000 resamples) to evaluate the accuracy of the nomogram.

\section{Results}

\section{Patient baseline data}

A total of 255 elderly patients with nondisplaced FNF were included in our study. Our analysis showed that the mean follow-up duration was 42.7 (24-60) months. The patients included 64 males and 191 females, with an average age of 73.2 years (range, 65-92). Among them, 28 patients experienced reoperation, and the most common reason was osteonecrosis of the femoral head (14 cases), followed by mechanical failure ( 8 cases) and nonunion (6 cases). None of the patients experienced deep infection or subtrochanteric fracture. All of the 28 patients underwent conversion surgery to arthroplasty.

\section{Univariate and multivariate analysis}

The interobserver reliability of the radiographic characteristics (Pauwel's classification and posterior tilt angle) was evaluated, and then initial demographical and perioperative variables were compared between the reoperation and non-reoperation groups (Tables 1 and 2). The data showed significant differences in age $(P=0.015)$, posterior tilt angle $(P=0.023)$, AST $(P=0.045)$, ALP $(P=0.012)$, ALB $(P=0.025)$, interval to weight-bearing $(P=0.001)$, Harris hip score $(P=0.004)$, and VAS $(P=0.016)$. According to Pauwel's classification, the most common fracture pattern in the reoperation group was Pauwel's III ( $n$ $=12,42.9 \%)$, followed by Pauwel's II $(n=9,32.1 \%)$ and
Table 1 Interobserver reliability of the radiographic characteristics

\begin{tabular}{llll}
\hline Characteristics & ICC or $\mathbf{k}$ & $\mathbf{9 5 \%} \mathbf{C l}$ & $\boldsymbol{P}$ value \\
\hline Pauwel's classification & 0.915 & 0.870 to 0.960 & $<0.001$ \\
Posterior tilt angle & 0.885 & 0.854 to 0.909 & $<0.001$ \\
\hline
\end{tabular}

Abbreviations: ICC intraclass correlation coefficient, $k$ kappa coefficient, $\mathrm{Cl}$ confidence interval

Pauwel's I ( $n=7,25.0 \%)$. On the other hand, Pauwel's II $(n=94,41.4 \%)$ was the most common fracture pattern in the non-reoperation group, followed by Pauwel's I ( $n=86$, $37.9 \%)$ and Pauwel's III $(n=47,20.7 \%)$, with a significant difference in the fracture pattern distribution $(P=0.031)$. Based on the $P<0.10$ threshold, all these risk factors and $\mathrm{Na}^{+}(P=0.080)$ were analyzed in the multivariable logistic regression to identify the independent risk factors for reoperation.

The multivariate analysis demonstrated that age (odds ratio $(\mathrm{OR})=0.910,95 \%$ confidence interval $(\mathrm{CI})=0.837-0.989, P$ $=0.026)$, posterior tilt angle $(\mathrm{OR}=2.986,95 \% \mathrm{CI}=1.143$ 7.797, $P=0.026)$, ALP $(\mathrm{OR}=4.033,95 \% \mathrm{CI}=1.275-12.756$, $P=0.018)$, ALB (OR $=5.345,95 \% \mathrm{CI}=1.577-18.116, P=$ 0.007), Pauwel's III classification $(\mathrm{OR}=5.056,95 \% \mathrm{CI}=$ $1.498-17.062, P=0.009$ ), and interval to weight-bearing (OR $=0.739,95 \% \mathrm{CI}=0.618-0.885, P=0.001$ ) were independent risk factors for reoperation after internal fixation of nondisplaced FNFs in elderly patients (Table 3).

\section{Development and validation of a reoperation nomogram}

Using the independent risk factors obtained from the multivariable logistic regression analyses, we constructed a nomogram to predict reoperation (Fig. 2). By adding individual scores of each predictor in the nomogram, the total score was obtained and used to calculate the corresponding reoperation probability. This was helpful for accurate evaluation of preoperative risks and determination of the reoperation cases. Our analyses showed high predictive accuracy and discrimination of the model, with a C- index of $0.850(95 \% \mathrm{CI}=0.803-0.913)$ and an AUC of 0.858 (Fig. 3). In addition, the corrected C-index was 0.811 in the bootstrapping validation. Besides, the calibration curve of the nomogram demonstrated good consistency between the actual diagnosed reoperation and the predicted probability (Fig. 4). Similarly, the nomogram DCA indicated that the model could be an excellent prediction tool for reoperation after internal fixation of nondisplaced FNFs in elderly patients (Fig. 5).

\section{Discussion}

In this study, we analyzed a total of 255 elderly patients to develop and validate a predictive clinical nomogram for reoperation after closed reduction and internal fixation of FNFs. Our findings showed that the reoperation rate within at least a 2 -year follow-up was $11.0 \%$, which 
Table 2 Characteristics of reoperation and non-reoperation patients

\begin{tabular}{|c|c|c|c|}
\hline Characteristics & Reoperation, $n=28(\%)$ & Non-reoperation, $n=227$ (\%) & $P$ value \\
\hline Gender & & & 0.362 \\
\hline Male & $9(32.1)$ & $55(24.2)$ & \\
\hline Female & $19(67.9)$ & $172(75.8)$ & \\
\hline Age & $68.0(67.0-73.0)$ & $72.0(67.0-78.0)$ & $0.015^{*}$ \\
\hline Injured side & & & 0.401 \\
\hline Right & $10(35.7)$ & $100(44.1)$ & \\
\hline Left & $18(64.3)$ & $127(55.9)$ & \\
\hline Smoking & & & 0.549 \\
\hline No & $25(89.3)$ & $210(92.5)$ & \\
\hline Yes & $3(10.7)$ & $17(7.5)$ & \\
\hline Alcohol consumption & & & 0.302 \\
\hline No & $26(92.9)$ & $219(96.5)$ & \\
\hline Yes & $2(7.1)$ & $8(3.5)$ & \\
\hline ASA classification & & & 0.411 \\
\hline $\mid-\|$ & $23(82.1)$ & $199(87.7)$ & \\
\hline III-IV & $5(17.9)$ & $28(12.3)$ & \\
\hline Chronic kidney disease & & & 0.435 \\
\hline No & $26(92.9)$ & $218(96.0)$ & \\
\hline Yes & $2(7.1)$ & $9(4.0)$ & \\
\hline Hypertension & & & 0.695 \\
\hline No & $11(39.3)$ & $98(43.2)$ & \\
\hline Yes & $17(60.7)$ & $129(56.8)$ & \\
\hline Diabetes mellitus & & & 0.205 \\
\hline No & $24(85.7)$ & $170(74.9)$ & \\
\hline Yes & $4(14.3)$ & $57(25.1)$ & \\
\hline Charlson's WIC & $3.54 \pm 1.26$ & $3.70 \pm 1.35$ & 0.541 \\
\hline Cerebrovascular disease & & & 0.425 \\
\hline No & $23(82.1)$ & $171(75.3)$ & \\
\hline Yes & $5(17.9)$ & $56(24.7)$ & \\
\hline COPD & & & 0.217 \\
\hline No & $24(85.7)$ & $210(92.5)$ & \\
\hline Yes & $4(14.3)$ & $17(7.5)$ & \\
\hline Preoperative functional status & & & 0.713 \\
\hline Using ambulatory aid & $2(7.1)$ & $21(9.3)$ & \\
\hline Independent ambulator & $26(92.9)$ & $206(90.7)$ & \\
\hline Interval to surgery & & & 0.335 \\
\hline$<72 \mathrm{~h}$ & $14(50.0)$ & $81(35.7)$ & \\
\hline $72-120 h$ & $7(25.0)$ & $72(31.7)$ & \\
\hline$>120 \mathrm{~h}$ & $7(25.0)$ & $74(32.6)$ & \\
\hline Pauwel's classification & & & $0.031^{*}$ \\
\hline I & $7(25.0)$ & $86(37.9)$ & \\
\hline$\|$ & $9(32.1)$ & $94(41.4)$ & \\
\hline III & $12(42.9)$ & $47(20.7)$ & \\
\hline Posterior tilt angle & & & $0.023^{*}$ \\
\hline
\end{tabular}


Table 2 Characteristics of reoperation and non-reoperation patients (Continued)

\begin{tabular}{|c|c|c|c|}
\hline Characteristics & Reoperation, $n=28$ (\%) & Non-reoperation, $n=227$ (\%) & $P$ value \\
\hline$\geq 20^{\circ}$ & $13(46.4)$ & $59(26.0)$ & \\
\hline$<20^{\circ}$ & $15(53.6)$ & $168(74.0)$ & \\
\hline Anesthesia type & & & 0.168 \\
\hline General anesthesia & $9(32.1)$ & $47(20.7)$ & \\
\hline Regional anesthesia & $19(67.9)$ & $180(79.3)$ & \\
\hline Surgical time (min) & $75.89 \pm 39.77$ & $80.68 \pm 29.64$ & 0.439 \\
\hline $\mathrm{WBC}\left(>10 \times 10^{9} / \mathrm{L}\right)$ & $2(7.1)$ & $35(15.4)$ & 0.392 \\
\hline $\mathrm{RBC}(<\text { lower limit })^{\mathrm{a}}$ & 8 (28.6) & 49 (21.6) & 0.403 \\
\hline $\operatorname{PLT}\left(>300 \times 10^{9} / \mathrm{L}\right)$ & $2(7.1)$ & $14(6.2)$ & 0.841 \\
\hline $\operatorname{LYM}\left(<1.1 \times 10^{9} / \mathrm{L}\right)$ & $10(35.7)$ & $80(35.2)$ & 0.961 \\
\hline $\operatorname{HGB}(<\text { lower limit })^{b}$ & $10(35.7)$ & $51(22.5)$ & 0.121 \\
\hline $\operatorname{ALT}(>40 \mathrm{U} / \mathrm{L})$ & $4(14.3)$ & $16(7.0)$ & 0.251 \\
\hline $\mathrm{AST}(>40 \mathrm{U} / \mathrm{L})$ & $4(14.3)$ & $11(4.8)$ & $0.045^{*}$ \\
\hline ALP (>125 U/L) & $7(25.0)$ & $21(9.3)$ & $0.012^{*}$ \\
\hline $\mathrm{Na}^{+}(<135 \mathrm{mmol} / \mathrm{L})$ & $7(25.0)$ & $29(12.8)$ & 0.080 \\
\hline $\mathrm{TP}(<60 \mathrm{~g} / \mathrm{L})$ & $8(28.6)$ & $41(18.1)$ & 0.183 \\
\hline ALB $(<35$ U/L) & $8(28.6)$ & $29(12.8)$ & $0.025^{*}$ \\
\hline D-dimer (> 0.5 mg/L) & $17(60.7)$ & $151(66.5)$ & 0.541 \\
\hline Interval to weight-bearing & $6.39 \pm 2.74$ & $8.24 \pm 2.73$ & $0.001^{*}$ \\
\hline Harris Hip Score & $76.68 \pm 7.69$ & $81.59 \pm 8.60$ & $0.004^{*}$ \\
\hline VAS & $2.57 \pm 1.60$ & $1.78 \pm 1.30$ & $0.016^{*}$ \\
\hline
\end{tabular}

Abbreviations: ASA the American Society of Anesthesiologists, WIC Charlson's weighted index of comorbidities, COPD chronic obstructive pulmonary diseases, WBC white blood cell, RBC red blood cell, $P L T$ platelet, $L Y M$ lymphocyte, HGB hemoglobin, ALT alanine transaminase, AST aspartate transaminase, ALP alkaline phosphatase, $N a+$ serum sodium concentration, $T P$ total protein, $A L B$ albumin

*: Statistically significant difference

a Reference range: women $3.5--5.0 \times 10^{12} / \mathrm{L}$, men $4.0--5.5 \times 10^{12} / \mathrm{L}$

b Reference range: women $110-150 \mathrm{~g} / \mathrm{L}$, men $120-160 \mathrm{~g} / \mathrm{L}$

Table 3 Multivariate analysis of risk factors associated with reoperation after internal fixation of nondisplaced FNFs in elderly patients

\begin{tabular}{|c|c|c|c|c|}
\hline Characteristics & OR & 95\% Cl (lower limit) & 95\% Cl (upper limit) & $P$ value \\
\hline Age & 0.910 & 0.837 & 0.989 & $0.026^{*}$ \\
\hline Posterior tilt angle & 2.986 & 1.143 & 7.797 & $0.026^{*}$ \\
\hline AST (> $40 \mathrm{U} / \mathrm{L})$ & 3.026 & 0.676 & 13.532 & 0.147 \\
\hline $\operatorname{ALP}(>125 \mathrm{U} / \mathrm{L})$ & 4.033 & 1.275 & 12.756 & $0.018^{*}$ \\
\hline $\mathrm{Na}^{+}(<135 \mathrm{mmol} / \mathrm{L})$ & 2.875 & 0.902 & 9.163 & 0.074 \\
\hline ALB (<35 U/L) & 5.345 & 1.577 & 18.116 & $0.007^{*}$ \\
\hline Interval to weight-bearing & 0.739 & 0.618 & 0.885 & $0.001^{*}$ \\
\hline \multicolumn{5}{|l|}{ Pauwel's classification } \\
\hline I & Ref. & & & \\
\hline$\|$ & 1.915 & 0.508 & 7.217 & 0.337 \\
\hline III & 5.056 & 1.498 & 17.062 & $0.009^{*}$ \\
\hline
\end{tabular}

Abbreviations: $O R$ odds ratio, $C l$ confidence interval, $A S T$ aspartate transaminase, $A L P$ alkaline phosphatase, $N a+$ serum sodium concentration, $A L B$ albumin *: Statistically significant difference 


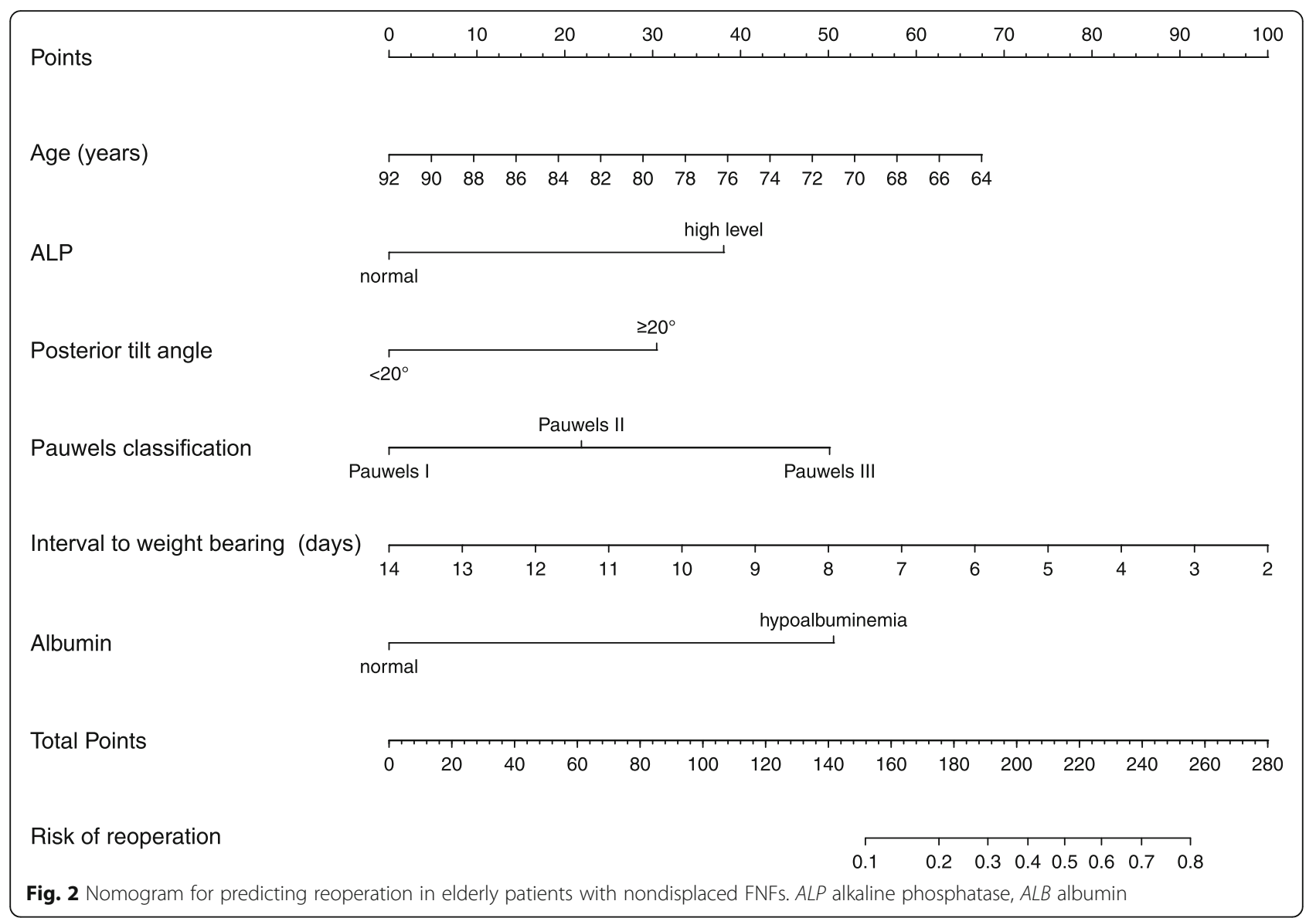

was consistent with previous reports $[8,9]$. Six key risk factors were included in the nomogram: preoperative posterior tilt angle, Pauwel's classification, age, preoperative ALP, preoperative ALB, and interval to weightbearing.

Reoperation after internal fixation of nondisplaced FNF in elderly patients could be precipitated by several factors, with posterior tilt angle having the highest prognostic value [12, 15, 22]. Currently, at least two mechanisms have been identified as main reasons for reoperation associated with preoperative posterior tilt angle. Firstly, the greater posterior tilt is associated with more posterior comminution of the femoral neck [22], which compromises the stability of internal fixation. Honkanen et al. [23] showed similar reoperation rate between nondisplaced FNF patients with $\geq 20^{\circ}$ posterior tilt angle and those with displaced FNF. Thus, the posterior tilt on lateral radiograph is as vital as displacement on the anteroposterior radiograph. Similarly, irreversible damage to the retinacular vessels which could result in either nonunion in the early stage or femoral head necrosis in the later stage has also been associated with reoperation [18]. In case of FNF with either varus angulation on the anteroposterior view or posterior tilt on the lateral view, the fragile lateral epiphyseal arteries could be torn or kinked, which would devastate the femoral head vitality [24]. Consistent with previous studies, our data showed that posterior tilt angle $\geq 20^{\circ}$ could predict reoperation in elderly patients with FNFs. Therefore, we suggest thorough evaluation of the preoperative lateral radiograph of hip joint to identify the patients with high posterior tilt angle.

In addition, Pauwel's classification is important and widely accepted in guiding treatment and rehabilitation of FNF [25]. In the present study, we analyzed the reoperation risk of patients with different Pauwel's classification. Both univariate and multivariate analyses showed that higher Pauwel's levels implied higher reoperation risks, which was in agreement with the finding obtained by Biz et al. [26]. They showed that the rates of internal fixation failure in patients with nondisplaced FNF had significant differences between Pauwel's II or III group and Pauwel's I group. In parallel, our study showed that only Pauwel's III FNF could predict reoperation. This could be because a vertical fracture line of Pauwel's III FNF is subjected to higher shear force and prone to inferior translation, and thus, early weight-bearing after surgery could challenge the stability of implants and lead 

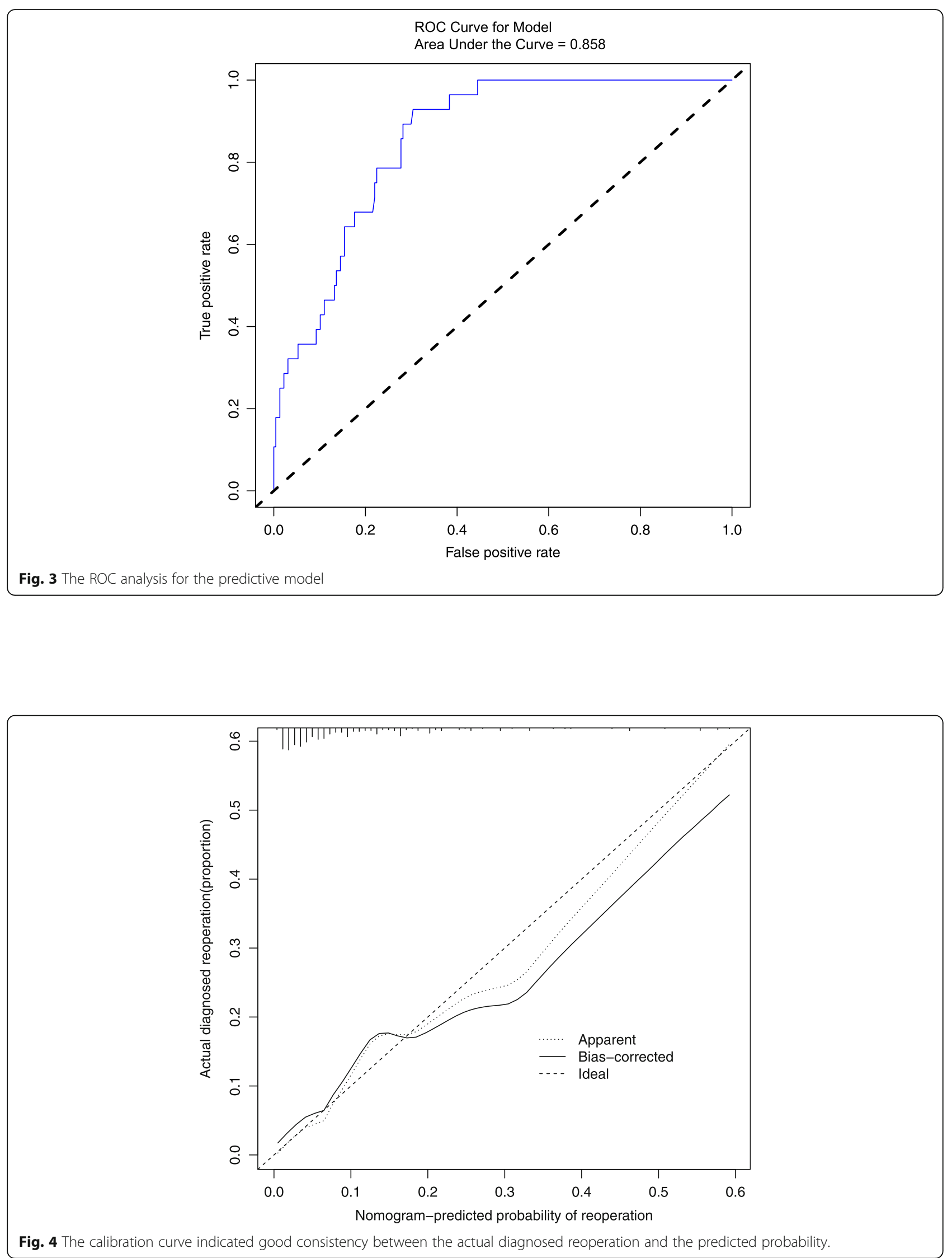

Fig. 4 The calibration curve indicated good consistency between the actual diagnosed reoperation and the predicted probability. 


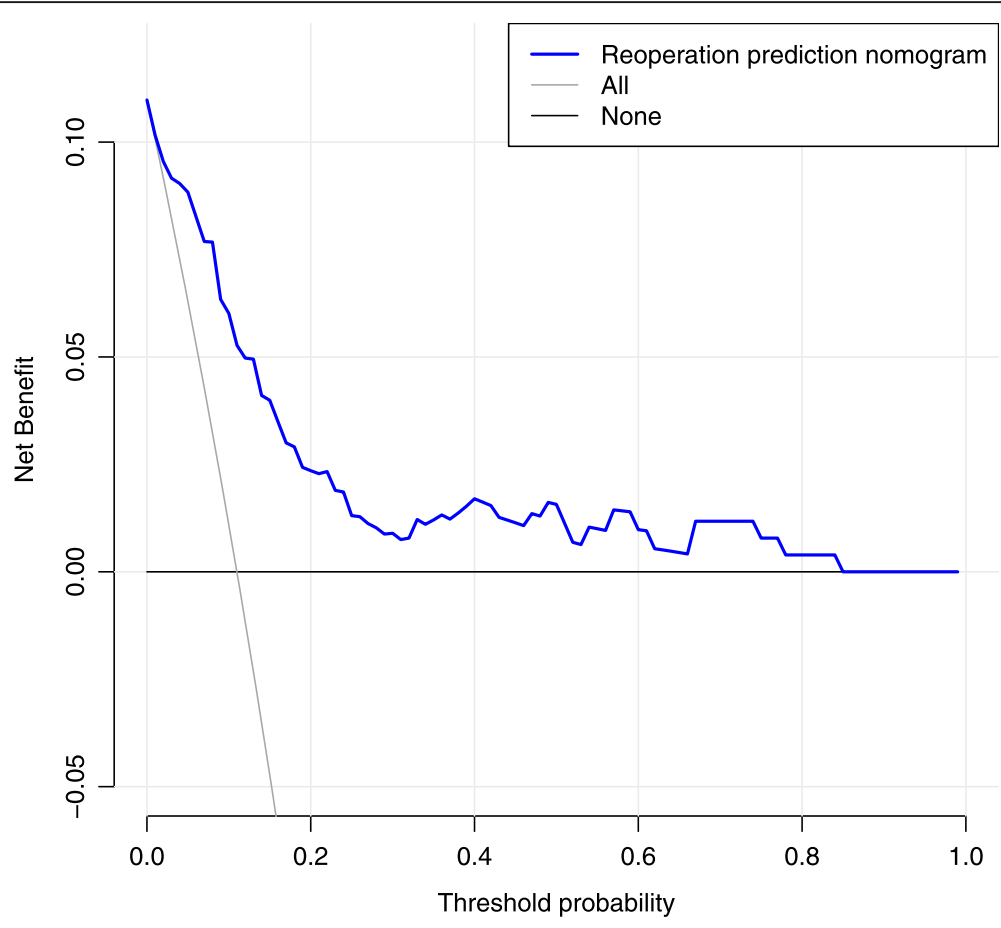

Fig. 5 Decision curve analysis for the reoperation nomogram

to failure of internal fixation $[27,28]$. Together, we demonstrate that, compared with internal fixation, elderly FNF patients with a Pauwel's III classification would benefit from primary arthroplasty by avoiding reoperation.

Although the effect of patient's age on reoperation after internal fixation of FNF in the elderly is important, the available data remains controversial. While other studies have demonstrated that advanced age is related with increase in reoperation $[15,29]$, others could not find any correlation between the age of the patients and the rate of reoperation [30, 31]. In contrast, our study showed that the younger patients in the elderly group were at a higher risk of revision surgery. This could be due to the fact that the younger individuals were not as frail and functionally impaired as the older ones; therefore, they were more sensitive to the complications of internal fixation. Indeed, a previous report by Rogmark et al. [31] demonstrated that younger patients in the elderly group had a higher frequency of reporting subjective pain after internal fixation compared with those with advanced age ( $51 \%$ vs $27 \%, p=0.016)$. In addition, the elderly patients with advanced age had a higher mortality rate compared with the younger ones, which could lead to underestimation of the number of possible reoperations [30], and thus might have influenced our findings.

High ALP levels were shown to predict reoperation in elderly patients with nondisplaced FNF in our study.
Since the ALP isoenzymes in serum could emanate from the liver, bone, or intestine, there is need to differentiate the elevated ALP from bone tumor, osteomalacia or hepatic diseases. Our study showed that the high levels of ALP were associated with reoperation and not any potential comorbidity. A potential cause might be that a lower BMD was also present in these patients. As a main biochemical marker of bone turnover, ALP is related with bone formation and mineralization. Tariq et al. [32] reported that ALP could be used to predict the BMD in postmenopausal females, and elevated ALP was associated with loss of BMD. In their study, Zhao et al. [33] showed a negative correlation between the ALP level and the BMD value of the femoral neck in patients with osteoporosis. Besides, it has been shown that the bone quality in elderly people plays an important role in the outcome of internal fixation [4]. In a biomechanical experiment, Sjöstedt et al. [34] showed that low BMD could weaken the strength of fixation. Hence, as an independent risk factor for reoperation, the ALP level should be integral in the evaluation of reoperation risk in the elderly patients with FNFs. On the other hand, low albumin level has been reported to be a significant risk factor for reoperation [12, 35]. However, data on the exact reason remains scant. Previous studies showed lower albumin level was associated with low BMD and recurrent falls after low-energy injury [36, 37]. In addition, we hypothesize that euthyroid sick syndrome (ESS) might 
be responsible for reoperation in patients with hypoalbuminemia. It has been shown that hypoalbuminemia correlated with ESS in elderly patients [38]. In recent studies, ESS was reported to correlate with perioperative anemia and metabolic disorder of Vitamin D, as well as parathyroid hormone $(\mathrm{PTH})[39,40]$, which could increase the possibility of reoperation after hip fractures $[41,42]$. However, due to the retrospective nature of our study, we could not evaluate the ESS due to missing data on the thyroid hormone profiles. Thus, prospective studies are required to determine the association between ESS and reoperation. Together, we suggest assessment of serum ALP and ALB alongside radiological measures for effective determination of the optimal surgical strategy: arthroplasty or internal fixation.

To date, there is lack of ideal protocol for weightbearing after internal fixation of nondisplaced FNF in elderly patients. Schwachmeyer et al. [43] suggested that patients with hip surgery should avoid early weightbearing after analyzing the hip contact loads in rehabilitation exercises. On the other hand, Kim et al. [44] showed that elderly FNF patients with full postoperative weight-bearing at an average of 5.2 days had excellent clinical and functional outcome. In our study, we showed that early weight-bearing after surgery would increase the incidence of reoperation. Besides increasing the risk of failure of internal fixation, early weightbearing could result in the occurrence reoperation through the following mechanisms. Firstly, owing to decreased bone quality in the elderly patients and bone resorption at the fracture site, early weight-bearing could lead to shortened femoral neck, which is a significant risk factor for osteonecrosis of the femoral head [45]. Secondly, since there is poor body control and insufficient arm strength in the elderly patients, it is difficult for them to perform partial weight-bearing exercise postoperatively. Early full weight-bearing would increase the intra-capsular pressure and result in high risk of osteonecrosis [46]. Our data showed that the elderly nondisplaced FNF patients would benefit from delayed weight-bearing postoperatively. However, the benefit of the delayed weight-bearing in reducing the reoperation rate must be balanced against potential complications due to bed rest, such as thrombosis, pneumonia, and increased mortality. Therefore, there should be a patienttailored postoperative rehabilitation strategy to decrease the risks for reoperation after FNF based on preoperative fracture pattern, serum biochemical markers, and the patients' general condition.

Having evaluated the potential risk factors such as radiological parameters, serum biochemical markers, and postoperative rehabilitation, we developed a nomogram for prediction of reoperation. The nomogram could inform individualized evaluation of reoperation risks in elderly patients who undergo internal fixation. Accordingly, primary arthroplasty could be used in patients with a high risk of reoperation as predicted by the constructed model. Furthermore, patients with high predictive value due to higher posterior tilt or Pauwel's angle could reduce the probability of reoperation by improving the postoperative variables such as weightbearing.

Our study successfully developed and validated a nomogram for prediction of reoperation following internal fixation of nondisplaced FNF in elderly patients. The nomogram is visual and user-friendly. However, our study was conducted retrospectively, and thus inherent selection bias might have affected our findings. Besides, the fixation operations were not performed by the same surgeon, which could affect the surgical outcomes. Some patients had indication for reoperation but could not be performed due to their general condition and fragility, which might have led to underestimation of the incidence of reoperation. In addition, since the nomogram was only validated internally, there is need for further external validation.

\section{Conclusion}

In summary, we successfully developed and validated a nomogram model for individualized prediction of reoperation after internal fixation of nondisplaced FNF in elderly patients based on perioperative variables. Based on the nomogram model, primary arthroplasty should be considered rather than internal fixation for elderly patients with high predictive values.

\section{Abbreviations}

FNF: Femoral neck fractures; ASA: American Society of Anesthesiologists; WIC: Charlson's weighted index of comorbidities; COPD: Chronic obstructive pulmonary diseases; WBC: White blood cell; RBC: Red blood cell; PLT: Platelet; LYM: Lymphocyte; HGB: Hemoglobin; ALT: Alanine transaminase;

AST: Aspartate transaminase; ALP: Alkaline phosphatase; $\mathrm{Na}^{+}$: Serum sodium concentration; TP: Total protein; ALB: Albumin; VAS: Visual analogue scale; K: kappa coefficient; ICC: Intraclass correlation coefficient; ROC: Receiver operating characteristic; C-index: Concordance index; DCA: Decision curve analysis; AUC: Area under receiver operating characteristic curve; OR: Odds ratio; Cl: Confidence interval; BMD: Bone mineral density; ESS: Euthyroid sick syndrome

\section{Acknowledgements \\ We appreciate the contribution of all patients, the investigators, and the medical staff.}

\section{Authors' contributions}

YZha and YZhu contributed to the study conception and design. Material preparation, data collection was performed by XD, YZha, and XC. HH and ZT analyzed and interpreted the data. The first draft of the manuscript was written by $\mathrm{JZ}$ and $\mathrm{HH}$. All authors commented on previous versions of the manuscript. The authors read and approved the final manuscript.

\section{Funding}

This study was supported by the Non-profit Central Research Institute Fund of the Chinese Academy of Medical Sciences [2019PT320001]. 


\section{Availability of data and materials}

The data contributing to this article may be made available upon request by sending an e-mail to the first author.

\section{Declarations}

\section{Ethics approval and consent to participate}

This study was approved by the clinical research ethics committee of the Third Affiliated Hospital of Hebei Medical University, and the number is K2015-001-12. Informed consent was obtained from all individual participants included in the study.

\section{Consent for publication}

Consent to publish was obtained from the patient detailed in this study.

\section{Competing interests}

All the authors declare that they have no conflict of interest with any organization that sponsored the research.

\begin{abstract}
Author details
'School of Medicine, Nankai University, Tianjin 300071, People's Republic of China. ${ }^{2}$ Department of Orthopedic Surgery, The Third Hospital of Hebei Medical University, Shijiazhuang 050051, People's Republic of China. ${ }^{3}$ Key Laboratory of Biomechanics of Hebei Province, Orthopedic Research Institution of Hebei Province, Shijiazhuang 050051, Hebei, People's Republic of China. ${ }^{4} \mathrm{NHC}$ Key Laboratory of Intelligent Orthopedic Equipment, The Third Hospital of Hebei Medical University, Shijiazhuang 050051, Hebei, People's Republic of China. ${ }^{5}$ Department of Orthopedics, Union Hospital, Tongji Medical College, Huazhong University of Science and Technology, Wuhan 430022, People's Republic of China.
\end{abstract}

Received: 12 July 2021 Accepted: 26 August 2021

Published online: 01 September 2021

\section{References}

1. Zheng J, Wang H, Gao Y, Ai Z. A study on the evaluation of a risk score of osteonecrosis of the femoral head based on survival analysis. J Arthroplasty. 2021;36(1):62-71. https://doi.org/10.1016/j.arth.2020.07.046.

2. Dolatowski FC, Frihagen F, Bartels S, Opland V, Šaltyte Benth J, Talsnes O, et al. Screw fixation versus hemiarthroplasty for nondisplaced femoral neck fractures in elderly patients: a multicenter randomized controlled trial. J Bone Joint Surg Am. 2019;101(2):136-44.

3. Xu DF, Bi FG, Ma CY, Wen ZF, Cai XZ. A systematic review of undisplaced femoral neck fracture treatments for patients over 65 years of age, with a focus on union rates and avascular necrosis. J Orthop Surg Res. 2017;12(1): 28. https://doi.org/10.1186/s13018-017-0528-9

4. Han SK, Song HS, Kim R, Kang SH. Clinical results of treatment of garden type 1 and 2 femoral neck fractures in patients over 70-year old. Eur J Trauma Emerg Surg. 2016;42(2):191-6. https://doi.org/10.1007/s00068-0150528-6.

5. Lu Q, Tang G, Zhao X, Guo S, Cai B, Li Q. Hemiarthroplasty versus internal fixation in super-aged patients with undisplaced femoral neck fractures: a 5year follow-up of randomized controlled trial. Arch Orthop Trauma Surg. 2017;137(1):27-35. https://doi.org/10.1007/s00402-016-2591-9.

6. Sjöholm P, Otten V, Wolf O, Gordon M, Karsten G, Sköldenberg O, et al. Posterior and anterior tilt increases the risk of failure after internal fixation of Garden I and II femoral neck fracture. Acta Orthop. 2019;90(6):537-41. https://doi.org/10.1080/17453674.2019.1637469.

7. Kain MS, Marcantonio AJ, lorio R. Revision surgery occurs frequently afte percutaneous fixation of stable femoral neck fractures in elderly patients. Clin Orthop Relat Res. 2014;472(12):4010-4. https://doi.org/10.1007/s11999014-3957-3

8. Oñativia IJ, Slullitel PA, Diaz Dilernia F, Gonzales Viezcas JM, Vietto V, Ramkumar PN, et al. Outcomes of nondisplaced intracapsular femoral neck fractures with internal screw fixation in elderly patients: a systematic review. Hip Int. 2018;28(1):18-28. https://doi.org/10.5301/hipint.5000532.

9. Mohit B. Fracture fixation in the operative management of hip fractures (FAITH): an international, multicentre, randomised controlled trial. Lancet. 2017;389(10078):1519-27.

10. Blomfeldt R, Törnkvist H, Ponzer S, Söderqvist A, Tidermark J. Displaced femoral neck fracture: comparison of primary total hip replacement with secondary replacement after failed internal fixation: a 2-year follow-up of 84 patients. Acta Orthop. 2006;77(4):638-43. https://doi.org/10.1080/17453 670610012728.

11. Frihagen F, Madsen JE, Aksnes E, Bakken HN, Maehlum T, Walløe A, et al. Comparison of re-operation rates following primary and secondary hemiarthroplasty of the hip. Injury. 2007;38(7):815-9. https://doi.org/10.1016/ j.injury.2006.09.020.

12. Bajada S, Smith A, Morgan D. Pre-operative nutritional serum parameters as predictors of failure after internal fixation in undisplaced intracapsular proximal femur fractures. Injury. 2015;46(8):1571-6. https://doi.org/10.1016/j. injury.2015.05.001.

13. Bigoni M, Turati M, Leone G, Caminita AD, D'Angelo F, Munegato D, et al. Internal fixation of intracapsular femoral neck fractures in elderly patients: mortality and reoperation rate. Aging Clin Exp Res. 2020;32(6):1173-8. https://doi.org/10.1007/s40520-019-01237-z.

14. Kane C, Jo J, Siegel J, Matuszewski PE, Swart E. Can we predict failure of percutaneous fixation of femoral neck fractures? Injury. 2020;51(2):357-60. https://doi.org/10.1016/j.injury.2019.10.068.

15. Okike K, Udogwu UN, Isaac M, Sprague S, Swiontkowski MF, Bhandari M, et al. Not all Garden-I and II femoral neck fractures in the elderly should be fixed: effect of posterior tilt on rates of subsequent arthroplasty. J Bone Joint Surg Am. 2019;101(20):1852-9.

16. Ma HH, Chou TA, Tsai SW, Chen CF, Wu PK, Chen WM. Outcomes of internal fixation versus hemiarthroplasty for elderly patients with an undisplaced femoral neck fracture: a systematic review and meta-analysis. J Orthop Surg Res. 2019;14(1):320. https://doi.org/10.1186/s13018-019-1377-5.

17. Roffman CE, Buchanan J, Allison GT. Charlson Comorbidities Index. J Physiother. 2016;62(3):171. https://doi.org/10.1016/j.jphys.2016.05.008.

18. Palm H, Gosvig K, Krasheninnikoff M, Jacobsen S, Gebuhr P. A new measurement for posterior tilt predicts reoperation in undisplaced femoral neck fractures: 113 consecutive patients treated by internal fixation and followed for 1 year. Acta Orthop. 2009;80(3):303-7. https://doi.org/10.3109/1 7453670902967281.

19. Gjertsen JE, Fevang JM, Matre K, Vinje T, Engesæter LB. Clinical outcome after undisplaced femoral neck fractures. Acta Orthop. 2011;82(3):268-74. https://doi.org/10.3109/17453674.2011.588857.

20. Pencina MJ, D'Agostino RB. Overall $C$ as a measure of discrimination in survival analysis: model specific population value and confidence interval estimation. Stat Med. 2004;23(13):2109-23. https://doi.org/10.1002/sim.1802.

21. Yin J, Yang Y, Ma K, Yang X, Lu T, Wang S, et al. Clinicopathological characteristics and prognosis of pulmonary pleomorphic carcinoma: a population-based retrospective study using SEER data. J Thorac Dis. 2018; 10(7):4262-73. https://doi.org/10.21037/jtd.2018.06.71.

22. Dolatowski FC, Adampour M, Frihagen F, Stavem K, Erik Utvåg S, Hoelsbrekken SE. Preoperative posterior tilt of at least $20^{\circ}$ increased the risk of fixation failure in Garden-I and -II femoral neck fractures. Acta Orthop. 2016;87(3):252-6. https://doi.org/10.3109/17453674.2016.1155253.

23. Honkanen JS, Ekman EM, Huovinen VK, Mäkelä KT, Koivisto M, Karvonen MP, et al. Preoperative posterior tilt increases the risk of later conversion to arthroplasty after osteosynthesis for femoral neck fracture. J Arthroplasty. 2021;5:S0883-5403(21):00411-3.

24. Kalsbeek J, van Walsum A, Roerdink H, Schipper I. More than $20^{\circ}$ posterior tilt of the femoral head in undisplaced femoral neck fractures results in a four times higher risk of treatment failure. Eur J Trauma Emerg Surg. 2021:1-8.

25. Shen M, Wang C, Chen H, Rui YF, Zhao S. An update on the Pauwels classification. J Orthop Surg Res. 2016;11(1):161. https://doi.org/10.1186/s13 018-016-0498-3.

26. Biz C, Tagliapietra J, Zonta F, Belluzzi E, Bragazzi NL, Ruggieri P. Predictors of early failure of the cannulated screw system in patients, 65 years and older, with non-displaced femoral neck fractures. Aging Clin Exp Res. 2020;32(3): 505-13. https://doi.org/10.1007/s40520-019-01394-1.

27. Cha YH, Yoo Jl, Hwang SY, Kim KJ, Kim HY, Choy WS, et al. Biomechanical evaluation of internal fixation of Pauwels type III femoral neck fractures: a systematic review of various fixation methods. Clin Orthop Surg. 2019;11(1): 1-14. https://doi.org/10.4055/cios.2019.11.1.1.

28. Liporace F, Gaines R, Collinge C, Haidukewych GJ. Results of internal fixation of Pauwels type-3 vertical femoral neck fractures. J Bone Joint Surg Am. 2008;90(8):1654-9.

29. Hui AC, Anderson GH, Choudhry R, Boyle J, Gregg PJ. Internal fixation or hemiarthroplasty for undisplaced fractures of the femoral neck in octogenarians. J Bone Joint Surg Br. 1994;76(6):891-4. 
30. Manohara R, Liang S, Huang D, Krishna L. Cancellous screw fixation for undisplaced femoral neck fractures in the elderly. J Orthop Surg (Hong Kong). 2014;22(3):282-6.

31. Rogmark C, Flensburg L, Fredin H. Undisplaced femoral neck fractures--no problems? A consecutive study of 224 patients treated with internal fixation. Injury. 2009;40(3):274-6. https://doi.org/10.1016/j.injury.2008.05.023.

32. Tariq S, Tariq S, Lone KP, Khaliq S. Alkaline phosphatase is a predictor of bone mineral density in postmenopausal females. Pak J Med Sci. 2019;35(3): 749-53. https://doi.org/10.12669/pjms.35.3.188.

33. Zhao D, Wang J, Liu Y, Liu X. Expressions and clinical significance of serum bone Gla-protein, bone alkaline phosphatase and C-terminal telopeptide of type I collagen in bone metabolism of patients with osteoporosis. Pak J Med Sci. 2015;31(1):91-4. https://doi.org/10.12669/pjms.311.6143.

34. Sjöstedt A, Zetterberg C, Hansson T, Hult E, Ekström L. Bone mineral content and fixation strength of femoral neck fractures. A cadaver study. Acta Orthop Scand. 1994;65(2):161-5. https://doi.org/10.3109/174536794 08995426.

35. Riaz O, Arshad R, Nisar S, Vanker R. Serum albumin and fixation failure with cannulated hip screws in undisplaced intracapsular femoral neck fracture. Ann R Coll Surg Engl. 2016;98(6):376-9. https://doi.org/10.1308/rcsann.2016. 0124.

36. D'Erasmo E, Pisani D, Ragno A, Raejntroph N, Letizia C, Acca M. Relationship between serum albumin and bone mineral density in postmenopausal women and in patients with hypoalbuminemia. Horm Metab Res. 1999; 31(6):385-8. https://doi.org/10.1055/s-2007-978760.

37. Hong X, Yan J, Xu L, Shen S, Zeng X, Chen L. Relationship between nutritional status and frailty in hospitalized older patients. Clin Interv Aging. 2019;14(1):105-11. https://doi.org/10.2147/CIA.S189040.

38. Girvent M, Maestro S, Hernández R, Carajol I, Monné J, Sancho JJ, et al. Euthyroid sick syndrome, associated endocrine abnormalities, and outcome in elderly patients undergoing emergency operation. Surgery. 1998;123(5): 560-7. https://doi.org/10.1067/msy.1998.87238.

39. Cauteruccio M, Vitiello R, Perisano C, Covino M, Sircana G, Piccirillo N, et al. Euthyroid sick syndrome in hip fractures: evaluation of postoperative anemia. Injury. 2020;51(Suppl 3):S9-S12.

40. Vitiello R, Perisano C, Covino M, Perna A, Bianchi A, Oliva MS, et al. Euthyroid sick syndrome in hip fractures: valuation of vitamin $D$ and parathyroid hormone axis. Injury. 2020;51 (Suppl 3):S13-6.

41. Halm EA, Wang JJ, Boockvar K, Penrod J, Silberzweig SB, Magaziner J, et al. The effect of perioperative anemia on clinical and functional outcomes in patients with hip fracture. J Orthop Trauma. 2004;18(6):369-74. https://doi. org/10.1097/00005131-200407000-00007.

42. Cazzato G, Masci G, Liuzza F, Capasso L, Florio M, Perisano C, et al. Secondary femur fracture following treatment with anterograde nailing: the state of the art. J Biol Regul Homeost Agents. 2018;32(6 Suppl. 1):151-5.

43. Schwachmeyer V, Damm P, Bender A, Dymke J, Graichen F, Bergmann G. In vivo hip joint loading during post-operative physiotherapeutic exercises. PLoS One. 2013;8(10):e77807. https://doi.org/10.1371/journal.pone.0077807.

44. Kim JW, Byun SE, Chang JS. The clinical outcomes of early internal fixation for undisplaced femoral neck fractures and early full weight-bearing in elderly patients. Arch Orthop Trauma Surg. 2014;134(7):941-6. https://doi. org/10.1007/s00402-014-2003-y.

45. Nanty L, Canovas F, Rodriguez T, Faure P, Dagneaux L. Femoral neck shortening after internal fixation of Garden I fractures increases the risk of femoral head collapse. Orthop Traumatol Surg Res. 2019;105(5):999-1004. https://doi.org/10.1016/j.otsr.2019.05.009.

46. Yen $\mathrm{CH}$, Leung HB, Tse PY. Effects of hip joint position and intra-capsular volume on hip joint intra-capsular pressure: a human cadaveric model. J Orthop Surg Res. 2009;4(8). https://doi.org/10.1186/1749-799X-4-8.

\section{Publisher's Note}

Springer Nature remains neutral with regard to jurisdictional claims in published maps and institutional affiliations.

Ready to submit your research? Choose BMC and benefit from:

- fast, convenient online submission

- thorough peer review by experienced researchers in your field

- rapid publication on acceptance

- support for research data, including large and complex data types

- gold Open Access which fosters wider collaboration and increased citations

- maximum visibility for your research: over $100 \mathrm{M}$ website views per year

At BMC, research is always in progress.

Learn more biomedcentral.com/submissions 